\title{
First organized screening mammography programme in Saudi Arabia: preliminary analysis of pilot round
}

S.S. Akhtar, ${ }^{1,2}$ H.M. Nadrah, ${ }^{3}$ M.A. Al-Habdan, ${ }^{3}$ S.A. El Gabbani, ${ }^{4}$ G.M.K. El Farouk, ${ }^{7}$ M.H. Abdelgadir ${ }^{5}$ and A.M. Al-Saigul ${ }^{3}$.

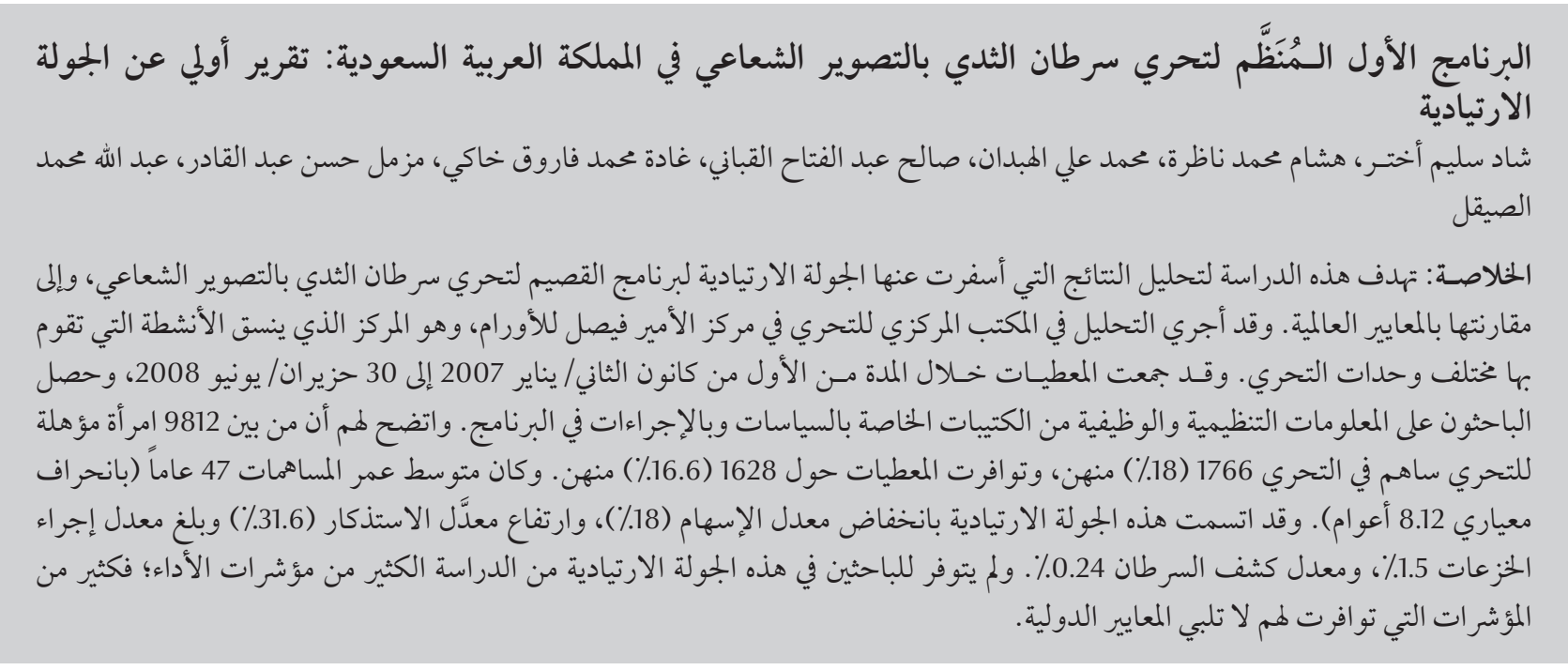

ABSTRACT The aim of this study was to analyse results of the pilot screening round for Al-Qassim Screening Mammography Programme and compare with international standards. Analysis was conducted in the central screening office in Prince Faisal Oncology Centre, which coordinates activities of various screening units. Data were collected during the period 1 January 2007 to 30 June 2008. Organizational and functional information was obtained from policy and procedure manuals of the programme. Out of 9812 eligible women, 1766 (18\%) participated and data were available for 1628 (16.6\%). The median age of participants was 47 (standard deviation $8.12)$ years. The low uptake rate $(18 \%)$ and a high recall rate $(31.6 \%)$ characterized the pilot screening round. Biopsy rate was $1.5 \%$ and cancer detection rate was $0.24 \%$. Many performance indicators in this pilot screening round were not available. Many of the available indicators did not meet international standards.

Premier programme de mammographie de dépistage en Arabie saoudite : rapport préliminaire de l'opération pilote

RÉSUMÉ Le but de cette étude était d'analyser les résultats de l'opération pilote de dépistage organisée dans le cadre du programme de mammographie de dépistage d'Al-Qassim, et de les comparer aux normes internationales. L'analyse a été effectuée dans le bureau central de dépistage de Prince Faisal Oncology Centre, qui

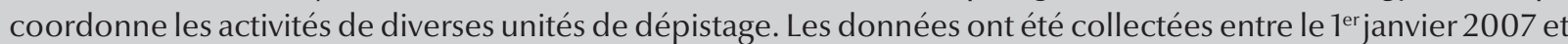
le 30 juin 2008. Les informations organisationnelles et fonctionnelles ont été extraites des manuels de politique et de procédures du programme. Sur 9812 femmes correspondant aux critères, 1766 d'entre elles (soit $18 \%$ ) ont participé à l'étude ; des données ont pu être collectées pour 1628 femmes (soit 16,6 \%). L'âge médian des participantes était de 47 ans (écart-type 8,12). L'opération pilote de dépistage s'est caractérisée par un faible taux de participation (18\%) et un taux de rappel élevé (31,6 \%). Le taux de biopsie était de 1,5\% et le taux de dépistage du cancer de 0,24 \%. Il manquait de nombreux indicateurs de performance dans cette opération. Enfin, un grand nombre des indicateurs disponibles ne satisfaisaient pas les normes internationales.

${ }^{7}$ Al-Qassim Screening Mammography Programme; ${ }^{5}$ Department of Family Medicine and Awareness Programme Committee, Al-Qassim Screening Mammography Programme, Buraidah, Al-Qassim, Saudi Arabia (Correspondence to S.S. Akhtar: shadsalim@hsshcc.org).

${ }^{2}$ Prince Faisal Oncology Centre, Buraidah, Al-Qassim, Saudi Arabia.

${ }^{3}$ Directorate of Health Services; ${ }^{4}$ Department of Family Medicine, Directorate of Health Services, Buraidah, Al-Qassim, Saudi Arabia.

Received: 30/05/10; accepted: 07/07/10 


\section{Introduction}

Large randomized controlled trials and meta-analyses have reported a significant decrease in breast cancer mortality in women through screening mammography $[1,2]$. As a result, many countries in Europe and North America have initiated national or regional screening mammography programmes for breast cancer [3]. The majority of the developing countries barely have resources to meet the basic needs of their population. The baseline incidence of breast cancer in these countries may still be too low to justify wide application of such population-based screening programmes. However, there is a documented increase in breast cancer incidence in most of these countries, and this is expected to rise further [4]. Since such programmes may take as long as a decade to become operationally effective, it is prudent that if resources exist, plans to decrease mortality due to breast cancer should be activated before it is too late.

According to the 2008 report of the World Health Organization, life expectancy of Saudi Arabian females is 73 years [5]. Saudi Arabia, an affluent country, spends $3.4 \%$ of its gross domestic product on health care. This is the equivalent of around US\$ 607 spent per capita annually [5]. Breast cancer is the commonest cancer seen in females in Saudi Arabia, and the majority of patients present with advanced stage of disease $[6,7]$. As resources are available, initiation of a population-based screening mammography programme is feasible.

As has been shown in the industrialized countries as well as in neighbouring countries, implementation and participation in screening mammography programmes may reduce the incidence of late stage of breast cancer at presentation, which may be an added advantage of such a programme in Saudi Arabia [7-9]. It is indeed recognized that the social and traditional values of the population may influence acceptance of such a programme. It is important to recognize that participation in breast cancer screening programmes is influenced by a multitude of local factors. Studies conducted in the Islamic Republic of Iran, Lebanon and Qatar have shown that participation in screening programmes may be affected by religious belief, fear of encounter with a male physician, embarrassment and fear of the test itself [10-12].

Recently, the pilot round of the population-based screening mammography programme conceived in the central Al-Qassim region of Saudi Arabia was concluded. This programme is expected to be the basis for a future national programme. We present here the preliminary analysis of the pilot round of this programme.

\section{Methods}

Approval for conducting this analysis was acquired from the regional ethics committee.

The organizational structure of the programme is shown in Figure 1. Unaizah is a mainly urban area of AlQassim region. It has a well-established network of primary health care centres (PHCs) connected by well-developed roads, telephones and the Internet to a secondary care hospital in the area, King Saud Hospital. Owing to its central location and proximity to Buraidah, the capital city of Al-Qassim region, Unaizah was selected for the pilot screening round. Another rural township, Okalatal Sakur, which has many desert dwellers living in the surrounding desert area of the region, was also included in the pilot project.

A public awareness team was constituted by community medicine experts and consisted of female Saudi Arabian nurses, female social workers and a committed group of female volunteers from the public. They held interactive sessions with females invited from the pilot areas to discuss the importance of screening mammography and the methods used. The public awareness campaign also included exhibitions, lectures, information stalls in shopping malls, and boards and banners displayed in the prominent areas of the region. The male members of the team held special sessions for the male residents of the pilot areas, and details of the programme were discussed. Community leaders, government officials, teachers, clergy and other persons of social importance were specially invited. The awareness campaign preceded the launch of actual screening by 6 months. The role of the media in this campaign was limited to the coverage of various events. The programme started recruiting from 1 January 2007 and the first round was completed on 30 June 2008.

Al-Qassim Screening Mammography Programme is aimed at women aged 35-60 years. The screening interval is 18 months. To be eligible, women should not be lactating or pregnant, and should have no breast symptoms. Exclusion criteria also included previous breast cancer, breast implants and a mammogram within the previous 18 months.

Digital mammography has the advantage of film-less digital storage, archiving at a distant site, easy retrieval and manipulation of images. Since there are data demonstrating the superiority of digital mammography over film mammography in younger women, it was decided to use only digital mammography units for this programme [13]. A team of radiologists and radiation physicists assessed the available mammography equipment in the region: 7 analogue units were available. After assessment the units were either upgraded to Computed Radiography System for mammography (CR) or replaced by Digital Mammography System (DR) units. Initially $2 \mathrm{DR}$ units were procured for the pilot project screening sites: a mobile unit (Selenia Full Field Digital Mammography System, Hologic) and 


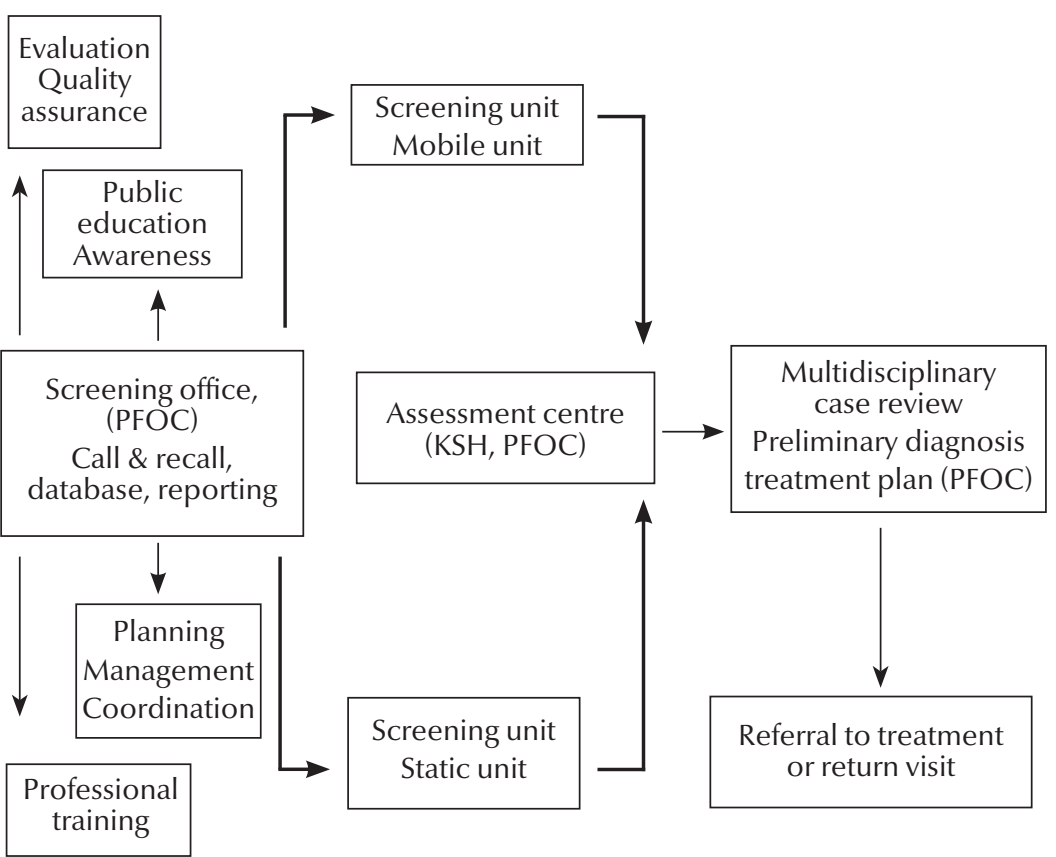

Figure 1 Organizational structure of Al-Qassim Screening Mammography Programme (PFOC = Prince Faisal Oncology Centre; KSH = King Saud Hospital, Unaizah)

another unit (Siemens, Mammomat Novation) was installed in King Saud Hospital, Unaizah. A DR unit (GE Senographe 2000D) and another CR unit (Agfa, Belgium) were located at King Fahd Specialist Hospital, a tertiary care referral hospital, in Buraidah. This

hospital has the only oncology centre (Prince Faisal Oncology Centre) in the region, where a regular breast health clinic is run. Two ultrasound machines with high-resolution probes and elastography facility (Hitachi, Japan and GE, United States of America) were

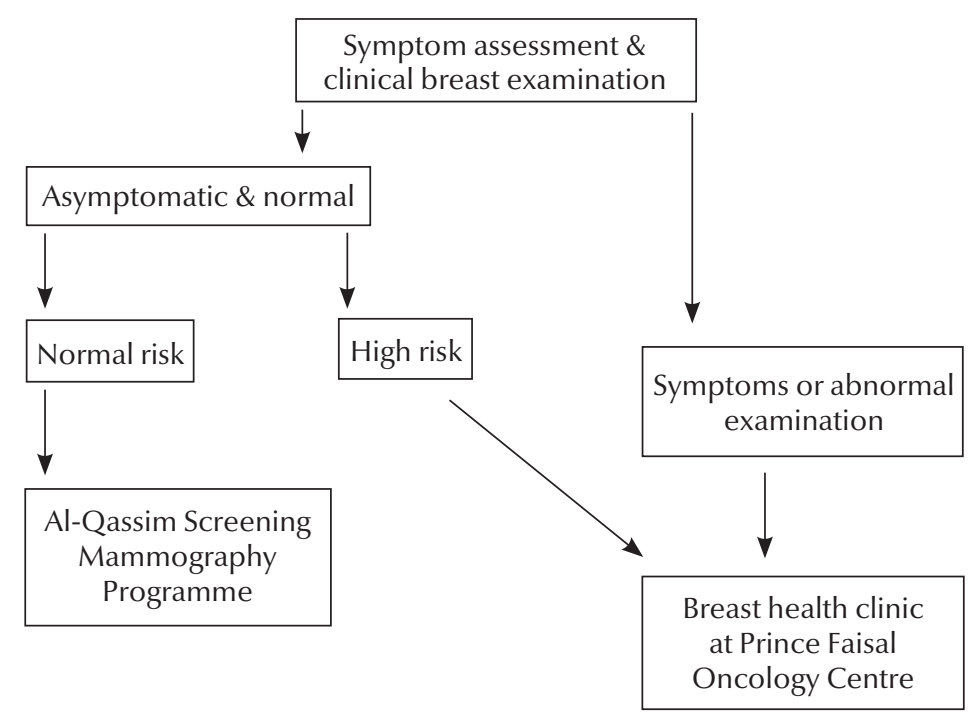

Figure 2 Al-Qassim Screening Mammography Programme: flow chart of the process at the primary health care centre (high risk: prior radiotherapy; number of first degree relatives with breast cancer; number of previous benign breast biopsies; atypical hyperplasia in a previous biopsy) installed for the pilot project, 1 at each hospital. Whenever required, the participants were referred to King Fahd Specialist Hospital for stereotactic biopsy procedures.

The screening units consisted of 2 radiologists and a team of radiographers and mammographers. Additional mammographers were selected from a pool of female Saudi technologists/nurses. A team of dedicated mammographers trained them for a period of 3 months prior to the start of programme. A female coordinator was designated as liaison between the participating teams at the static and mobile units. The mobile unit was stationed at the 30-bed hospital in Okalat-al Sakur region to cater to that area. The DICOM (Digital Imaging and Communication in Medicine) images were digitally archived and read at the central reporting office at King Fahd Specialist Hospital. Data were stored in a locally developed database programme.

The mammography screening comprised 2 views, craniocaudal and mediolateral oblique. Two radiologists read the images independently, and only in the event of consensus was the decision taken either to investigate the patient further or return her to a routine followup. In case of discordance between the 2 radiologists, a third reading by a senior member of the central team was taken as decisive.

In Al-Qassim region medical records of almost all the inhabitants are maintained at the local PHC. From these files, the PHC department prepared a list of registered females in the areas selected for the pilot round. For each PHC, women of eligible age group were short-listed with their contact numbers and address. In each PHC, a coordinator was designated to communicate with eligible females and the screening unit. Every eligible woman was contacted and, after checking exclusion criteria, invited to the PHC where demographic data were recorded on a previously drafted form. Risk category 


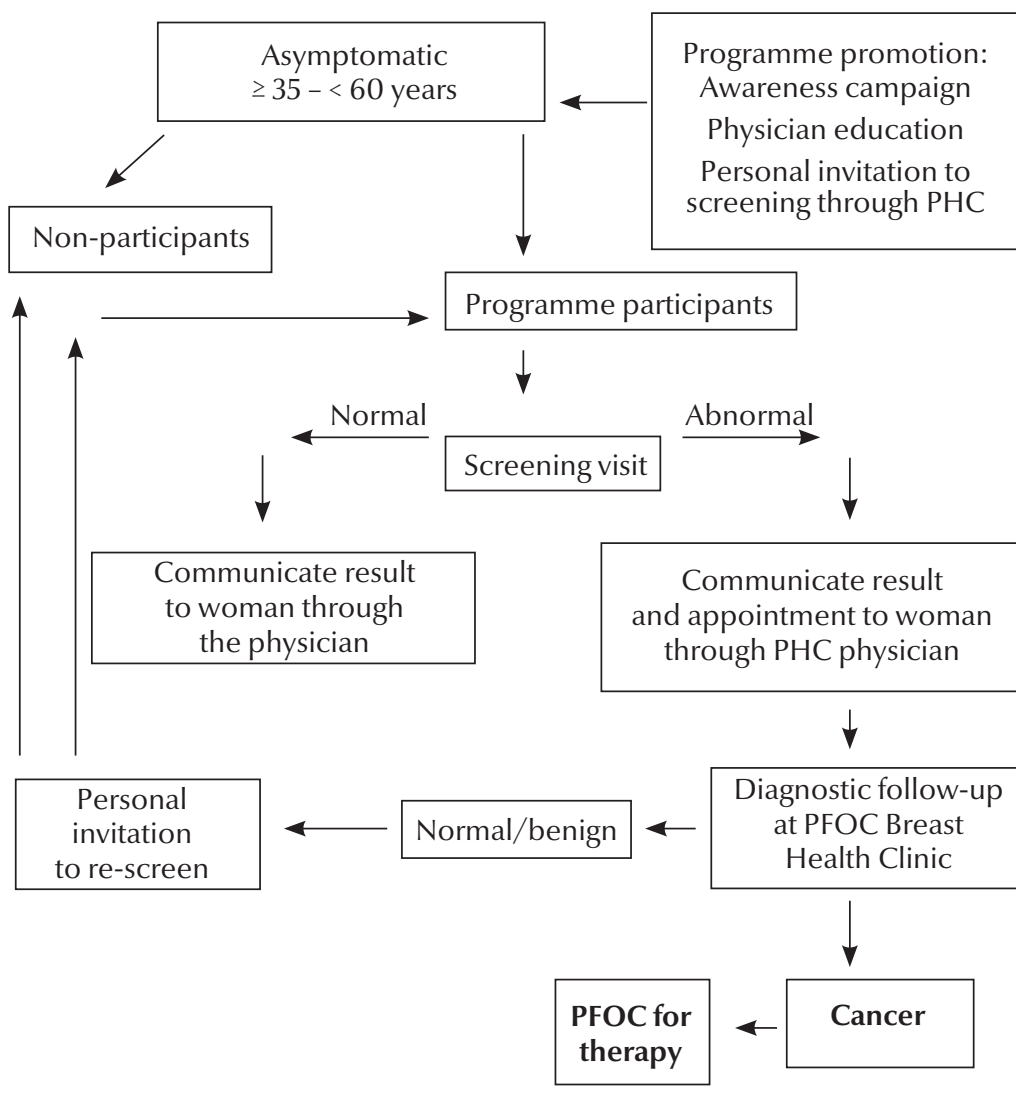

Figure 3 Al-Qassim Screening Mammography Programme: flow chart of screening process $(\mathrm{PHC}=$ primary health care centre; $\mathrm{PFOC}=$ Prince Faisal Oncology Centre $)$

was identified and any contraindications for screening mammography were excluded. The coordinator secured appointments for screening as well as subsequent assessment of the clients according to their convenience and menstrual cycle. The assessment protocol at the $\mathrm{PHC}$ and a flow diagram of the programme are shown in Figures 2 and 3 respectively. Commencement of the programme was announced through various media channels, newspapers and display posters in the region. The screening results were communicated through the PHC and for those recalled an appointment was made in the assessment clinics at King Saud Hospital or King Fahd Specialist Hospital.

Details of participants undergoing any kind of biopsy procedure were discussed in the multidisciplinary team meetings. Those needing therapy were referred to Prince Faisal Oncology Centre (Figure 3).

\section{Results}

According to the 2004 census, the total number of Saudi Arabian women in Al-Qassim region was 409 970, of whom 74476 were aged 35-60 years [14]. Out of these, 9812 resided in the 2 health care sectors selected for the pilot screening round and these constituted the target group. Only 1766 responded to the call and attended the screening round, resulting in an uptake rate of $17.99 \%$ for the first 18-month cycle of the programme.

Data were available for 1628 clients in the temporary database developed for the purpose. The median age of the participants was 47 (standard deviation 8.12 ) years and the mean was 46.8 years. Age distribution of the participants is shown in Table 1: 54 of the participating women were over 60 years and 6 were over 70 years.
Following the initial screening round, 925 (56.82\%) women were sent back to return for a routine round after 18 months, while as 515 (31.6\%) were recalled for an early reassessment. For 188 women (11.5\%) there was no information about follow-up in the database. The detailed performance and quality indicators of the pilot round are shown in Table 2.

Tables 1 and 3 show the biopsy, cancer detection rate and follow-up as related to the age groups screened. Our early recall rate ranged from $28.2 \%$ in 51-55 age group to a very high of $41.2 \%$ in women $>70$ years of age (Table 1). As shown in Table 3, no invasive cancer was detected in women younger than 40 years of age in this pilot round.

\section{Discussion}

In a previous study from Al-Qassim, around $50 \%$ of women residing in the region had never heard about breast self examination, and those who had did not practise it regularly [15]. Improving awareness and practice rates of breast self examination among the population could be an easy and cost-effective method for early detection of breast cancer in a country with different cultural, ethnic and racial make-up. However, a recent trial involving 300000 women in another developing country, China, indicated that breast self examination did not reduce breast cancer mortality rates [16]. Screening mammography therefore, remains the method of choice to decrease mortality due to breast cancer. Organized screening programmes can ensure quality control of the screening process and monitor interim indicators showing whether the programme is on track towards achieving a reduction in breast cancer mortality in the population. Conversely, opportunistic programmes such as charity or fee for service programmes are delivered in an ad hoc fashion without targeting or recalling women who are most likely to 


\begin{tabular}{|c|c|c|c|c|c|c|c|}
\hline \multirow[t]{3}{*}{ Age group (years) } & \multirow{3}{*}{$\begin{array}{l}\text { No. women } \\
\text { screened }\end{array}$} & \multicolumn{6}{|c|}{ Type of recall } \\
\hline & & \multicolumn{2}{|c|}{ Routine } & \multicolumn{2}{|c|}{ Early } & \multicolumn{2}{|c|}{ No information } \\
\hline & & No. & $\%$ & No. & $\%$ & No. & $\%$ \\
\hline$\leq 40$ & 353 & 221 & 62.6 & 104 & 29.5 & 28 & 7.9 \\
\hline $41-45$ & 346 & 199 & 57.5 & 111 & 32.1 & 36 & 10.4 \\
\hline $46-50$ & 401 & 212 & 52.9 & 139 & 34.7 & 50 & 12.5 \\
\hline $51-55$ & 294 & 176 & 59.9 & 83 & 28.2 & 35 & 11.9 \\
\hline $56-60$ & 158 & 80 & 50.6 & 55 & 34.8 & 23 & 14.6 \\
\hline $61-65$ & 37 & 19 & 51.4 & 12 & 32.4 & 6 & 16.2 \\
\hline$>65$ & 17 & 8 & 47.1 & 7 & 41.2 & 2 & 11.8 \\
\hline Unknown & 22 & 10 & 45.5 & 4 & 18.2 & 8 & 36.4 \\
\hline Total & 1628 & 925 & 56.8 & 515 & 31.6 & 188 & 11.5 \\
\hline
\end{tabular}

benefit from screening mammography. A recent study comparing the 2 types of screening has confirmed the higher sensitivity of a population-based programme [17]

Al-Qassim Screening Mammography Programme is the first organized population-based screening mammography programme in Saudi Arabia.Itwasimperativethat resultswere compared to international standards to confirm that the programme was achieving its goals.

The uptake of our pilot screening round (17.9\%) was much lower than reported in similar pilot projects conducted in Europe: $42 \%-45 \%$ in a Swiss pilot project, $36.7 \%$ in a French pilot programme, $36 \%$ in Luxembourg and $45.1 \%$ in a first round in Hungary [18-21]. Our uptake rate was much lower than the standard figure of more

\begin{tabular}{|c|c|c|c|}
\hline \multirow[t]{2}{*}{ Indicator } & \multirow{2}{*}{$\begin{array}{l}\text { Present } \\
\text { series }\end{array}$} & \multicolumn{2}{|c|}{ International standard } \\
\hline & & EU [14] & UK [15] \\
\hline $\begin{array}{l}\text { No. of women eligible for pilot project in } \\
\text { the } 2 \text { health sectors (target population) }\end{array}$ & 9812 & & \\
\hline No. of women screened & 1766 & & \\
\hline Uptake rate (\%) & 17.9 & $>75$ & $>75$ \\
\hline No. of women for whom data were available & 1628 & & \\
\hline No. of women recalled & 515 & & \\
\hline Recall rate $^{a}(\%)$ & 31.6 & $<5$ & $<7$ \\
\hline Total No. of biopsies ${ }^{b}$ & 25 & & \\
\hline Biopsy rate (\%) & 1.5 & & \\
\hline Biopsy rate among recalled patients ${ }^{\mathrm{a}}(\%)$ & 4.85 & & \\
\hline Benign biopsy rate per 1000 screened & 12.3 & & $<3.6$ \\
\hline Total no. of cancers detected & 5 & & \\
\hline No. of invasive cancers & 4 & & \\
\hline Cancer detection rate per 1000 screened & 2.45 & & $>1.5$ \\
\hline DCIS per 1000 screened & 0.61 & & $>0.4-<0.9$ \\
\hline DCIS (\% of malignant cases) & 20 & $>15$ & \\
\hline
\end{tabular}

${ }^{a}$ Total number biopsies/number of women recalled for assessment $\times 100$. ${ }^{b}$ Includes stereotactic core biopsies, fine needle aspiration cytology and open surgical biopsies. $E U=$ European Union; $U K=$ United Kingdom; DCIS=duct carcinoma in situ . than $70 \%$ recommended by the European Union and the United Kingdom $[22,23]$

The factors known to influence first time attendance for screening include being married, working, low or middle levels of education and income, misinformation, ineffective health communication, competing priorities, participating in early detection practices, perceiving mammography as a sensitive technique for detecting breast cancer and seeing oneself as susceptible to breast cancer $[24,25]$. Indeed the characteristics and demography of our population were quite unlike the Europeans, with strong cultural differences. These could have had a bearing on uptake rate in our programme. In future, it would be interesting to analyse the factors and barriers affecting the participation by the eligible population of this region.

The recall rate, $31.6 \%$, for early assessment in the pilot screening round was much higher than the international guidelines set by the European Union and the United Kingdom (Table 2). According to European Union guidelines, the proportion of women recalled for early assessment should be less than $7 \%$ in an initial screening examination, and the desirable level is below 5\% [22]. In a review of European programmes, the recall rate varied from $1.3 \%-18.4 \%$ 


\begin{tabular}{|c|c|c|c|c|}
\hline Age group (years) & Benign & DCIS & Invasive cancer & Total \\
\hline$<40$ & 4 & 1 & 0 & 5 \\
\hline $41-45$ & 4 & 0 & 1 & 5 \\
\hline $46-50$ & 8 & 0 & 2 & 10 \\
\hline$\geq 51$ & 3 & 0 & 0 & 3 \\
\hline Unknown & 0 & 0 & 1 & 1 \\
\hline Total & 19 & 1 & 4 & 24 \\
\hline
\end{tabular}

DCIS = duct carcinoma in situ.

[26]. In another comparative assessment of performance indicators of international screening mammography programmes in 14 countries, recall rate on initial screening varied from $1.4 \%$ in the Netherlands to $15.1 \%$ in the United States of America [27].

A decline in recall rate across age and in subsequent screens has also been documented [27]. We did not note a decline in the recall rate with increasing age: in our pilot round, recall rate was lowest in the age group $51-55$ years $(28.2 \%)$ and highest in women aged over 65 years $(41.2 \%)$.

A high recall rate causes psychological morbidity and indicates inefficient use of screening resources and women have to undergo unnecessary and costly follow-up investigations. At the same time, too low a recall rate may decrease the detection rate and increase the incidence of subsequent interval cancers. Double reading by consensus or arbitration reportedly decreases the recall rate [28]. This is standard practice in our programme, hence should have decreased the recall rate. Numerous explanations could be hypothesized to explain our high recall rate: our physicians may tend to recall women with suspicious findings, even in the absence of a possibility of cancer, to avoid possible malpractice litigation; our mammography readers are low-volume readers by definition, interpreting around 100 mammograms a month; interpreting a high volume of mammograms is known to lessen the recall rate [29].

Other factors, which are known to have an impact on the recall rate include the age of the screened population, type of mammography equipment used, technical problems and training of the mammography staff. It would be interesting to analyse the reasons for the high recall rate in a future study.

In French pilot and Norwegian programmes the biopsy rate was similar to our rate: $1.2 \%$ and $1.9 \%$ respectively $[19,30]$. The biopsy rate may be related to the rate of recall. A higher recall rate will decrease the proportion of women biopsied among those recalled compared to a programme with a low recall rate. The number of biopsies related to the total number screened, of course, remains constant. The biopsy rate among our recalled women was $4.85 \%$, which is quite low compared to $39.2 \%$ in the Norwegian programme [30].

The cancer detection rate in this first screen, also called prevalent screen, was $0.24 \%$. Cancer detection rate depends upon baseline incidence of breast cancer in the population. Consequently, the detection rate in our programme was lower than even those European countries that have the lowest detection rates, Finland $0.37 \%$ and Hungary $0.36 \%[21,31]$.

\section{Conclusion}

Many performance indicators of the pilot round of Al-Qassim Screening Mammography Programme were not available. Many of those available did not meet recommended international standards. There is an urgent need to review and revise the whole programme in order to achieve the following goals:

- increase the participation rate,

- decrease the recall rate,

- improve the detection rate,

- develop or procure a purpose-built database with trained staff to receive, enter and analyse the data.

\section{Acknowledgements}

The authors would like to thank Dr Salah Al Kharas, the Director General Health Affairs Al-Qassim, and Dr Atef Mohammed Saroor, Director General Audit, Ministry of Health, Saudi Arabia, for their logistic support. The authors also wish to thank Dr Imran-Ul-Haque, Consultant Histopathologist, Prince Faisal Oncology Centre, and Dr Mohammed Mahmoud Sami, Specialist Radiologist, Al-Qassim Screening Mammography Programme, for their contribution to the programme.

The pilot screening round of AlQassim Screening Mammography Programme utilized the available resources of the Ministry of Health. 
1. Elmore JG et al. Clinical Review: Screening for breast cancer. Journal of the American Medical Association, 2005, 293:12451256.

2. Fletcher SW, Elmore JG. Clinical practice: mammographic screening for breast cancer. New England Journal of Medicine, 2003, 348:1672-1680.

3. International Cancer Screening Network: Organized PopulationBased Breast Cancer Screening Programs in 22 Countries Surveyed in 1995, USA, NCl, and Updated 2007 (http:// appliedresearch.cancer.gov/icsn/breast/screening.html, accessed on 1st September 2010).

4. Potter P. Perspective: "Westernizing" women's risks? Breast cancer in lower income countries. New England Journal of Medicine, 2008, 358:213-216.

5. WHO Country profile, Saudi Arabia. Geneva, World Health Organization, 2008 (http://www.who.int/countries/sau/en/, accessed 10 August 2010).

6. Khatib O, Aljurf M. Cancer prevention and control in the Eastern Mediterranean region: the need for a public health approach. Hematology/oncology and stem cell therapy, 2008, 1:44-52.

7. Akhtar SS, Nadrah HM. Assessment of the quality of breast cancer care: a single institutional study from Saudi Arabia. International Journal for Quality in Health Care, 2005, 17:301-305.

8. Taplin $\mathrm{SH}$ et al. Evaluating organized breast cancer screening implementation: the prevention of late-stage disease? Cancer Epidemiology, Biomarkers \& Prevention, 2004, 13:225-234.

9. Tarabeia J et al. A comparison of trends in incidence and mortality rates of breast cancer, incidence to mortality ratio and stage at diagnosis between Arab and Jewish women in Israel, 1979-2002. European Journal of Cancer Prevention, 2007, 16:36-42.

10. Hatefnia E et al. Correlates of mammography utilization among working Muslim Iranian women. Health Care for Women International, 2010, 31:499-514.

11. Adib SM et al. Research in action: mammography utilization following breast cancer awareness campaign in Lebanon 2002-05. Eastern Mediterranean Health Journal, 2009, 15:6-18.

12. Bener $\mathrm{A}$ et al. Do we need to maximize the breast cancer screening awareness? Experience with an endogenous society with high fertility. Asian Pacific Journal of Cancer Prevention, 2009, 10:599-604.

13. Pisano ED et al. Diagnostic performance of digital versus film mammography for breast-cancer screening. New England Journal of Medicine, 2005, 353:1773-1783.

14. KSA census for the year 2004. Riyadh, Ministry of Planning, Saudi Arabia (http://www.cdsi.gov.sa/showproductstandard. aspx?lid=26\&pid=1658, accessed 8 April 2009).

15. Akhtar SS et al. Beliefs and attitudes about breast self examination in Al-Qassim region of Saudi Arabia. A study of women attending primary health care centres. Saudi Medical Journal, 1995, 16:493-497.
16. Thomas DB et al. Randomized trial of breast self examination in Shanghai: final results. Journal of the National Cancer Institure, 2002, 94:1445-1447.

17. Bihrmann $\mathrm{K}$ et al. Performance of systematic and non-systematic ('opportunistic') screening mammography: a comparative study from Denmark. Journal of Medical Screening, 2008, 15:23-26.

18. Bulliard JL., De Landtsheer JP, Levi F. Results from the Swiss mammography screening pilot programme. European Journal of Cancer, 2003, 39:973-978.

19. Wait $\mathrm{SH}$, Allemand HM. The French breast cancer screening programme. Epidemiological and economic results of the first round of screening. European Journal of Public Health, 1996, 6:43-48.

20. Autier $\mathrm{P}$ et al. A breast screening progrmamme operating in a liberal helath care system: the Luxembourg mammography programme 1992-1997. International Journal of Cancer, 2002, 97:828-832.

21. Boncz I et al. The organization and results of first screening round of the Hungarian nationwide organized breast cancer screening programme. Annals of Oncology, 2007, 18:795-799.

22. Perry $\mathrm{N}$ et al. European guidelines for quality assurance in breast cancerscreening and diagnosis, 4th ed. Brussels, European Community, 2006 (http://www.euref.org/ND7306954ENC_002. pdf, accessed 10 August 2010).

23. Saving lives through screening: NHS breast screening programme annual review 2008. London, NHS, Cancer Screening Programmes, 2008 (http://www.cancerscreening.nhs.uk/ breastscreen/publications/nhsbsp-annualreview2008.pdf, accessed 10 August 2010).

24. Aro AR et al. Psychosocial predictors of first attendance for organized mammography screening. Journal of Medical Screening, 1996, 6:82-88.

25. Lamyian $\mathrm{M}$ et al. Barriers to and factors facilitating breast cancer screening among Iranian women: a qualitative study. Eastern Mediterranean Health Journal, 2007, 13:1160-1169.

26. Lynge $\mathrm{E}$ et al. Reporting of performance indicators of mammography screening in Europe. European Journal of Cancer Prevention, 2003, 12:213-222.

27. Yankaskas BC et al. International comparison of performance measures for screening mammography: can it be done? Journal of Medical Screening, 2004, 11:187-193.

28. Kopans D. Double reading. Radiologic Clinics of North America, 2000, 38:719-724.

29. Esserman L et al. Improving the accuracy of mammography: volume and outcome relationships. Journal of the National Cancer Institute, 2002, 94:369-374.

30. Hofvind $\mathrm{S}$ et al. Using the European guidelines to evaluate the Norwegian breast cancer screening program. European Journal of Epidemiology, 2007, 22:447-455.

31. Dean PB, Pamilo M. Screening mammography in Finland-1.5 million examinations with 97 percent specificity. Acta Oncologica, 1999, 38:47-54. 